\title{
Optimasi Parameter-Parameter Energi Pada Clutch Point Konverter Torsi Melalui Variasi Rasio Putaran
}

\author{
Widyastutifajri Nuha ${ }^{1}$, W.M. Rumaherang ${ }^{1}$ J. Louhenapessy $^{1}$ \\ ${ }^{1}$ Jurusan Teknik Mesin Fakultas Teknik Universitas Pattimura, Ambon 97233 \\ *n.widy04@gmail.com
}

\begin{abstract}
Abstrak. Konverter torsi adalah transmisi hidrodinamik yang berfungsi untuk memindahkan daya dan melipatgandakan momen dari poros penggerak ke poros beban secara halus dengan bantuan oli sebagai fluida kerja. Titik kopling (clutch point) pada karakteristik konverter torsi adalah titik kerja dimana terjadi keseimbangan momen pompa dan turbin. Permasalahan utama dalam desain dan operasi konverter torsi adalah bahwa pada putaran yang diinginkan, titik kopling tercapai dan semua parameter energi harus mencapai nilai optimum. Tulisan ini membahas pengaruh rasio putaran (i) terhadap parameter momen dan efisiensi serta menentukan nilai optimum dan clutch point secara teroritis dan experimental. Hasil perhitungan dan ekspeimen menunjukan bahwa nilai momen turbin berkurang dengan naiknya rasio putaran, sedangkan nilai momen pompa turun setelah clutch point tercapat, yaitu pada nilai rasio putaran $\mathrm{i}=0,82$. Pada clutch point kondisi kerja optimum pada efesiensi maksimum $\eta_{\max }=0,86$.
\end{abstract}

Kata Kunci : Konverter torsi, karakteristik energi, titik kopling

\begin{abstract}
The torque converter is a hydrodynamic transmission which functions to transfer power and smoothly multiply the moment value from the drive to the load shafts byoil as the working fluid. The clutch point of the torque converter characteristic is the working point where the pump and turbine moments in a state of equilibrium. The main problem in the design and operation of the torque converter is that at the desired speed, reach the coupling point, and all energy parameters must reach the optimum value. This paper will discuss the effect of the rotation ratio on the moment and efficiency parameters and determine the optimum value and clutch point theoretically and experimentally. The results of calculations and experiments show that the turbine moment value decreases with increasing rotation ratio, while the pump moment value decrease after the clutch point. The clutch point was founded at the rotation ratio value $i=0.82$. At this point, the optimum conditions at the maximum efficiency $\eta_{\max }=0.86$.
\end{abstract}

Keywords: Torque converter, energy characteristics, clutch point

\section{PENDAHULUAN}

Peningkatan efesiensi system permesinan dalam industry menjadi masalah yang menjadi perhatian penting sampai saat ini. Salah satu upaya peningkatan efesiensi adalah peningkatan efesiensi system transmisi. Sistem transmisi terdiri dari transmisi mekanik dan hidrostatik dan hidrodinamik yaitu konverter torsi digunakan secara luas untuk berbagai aplikasi permesinan yang membutuhkan transmisi daya halus seperti automobile, loader industry, forklift, dan transmisi pada sistem propulsi kapal. Konverter torsi memindahkan daya dan putaran dari motor induk ke sistem transmisi secara halus dengan meredam getaran engine sehingga mesin berputar secara halus dan efisien [1]. Konverter torsi terdiri atas tiga komponen utama yaitu : (1) Pompa, yang terhubung langsung ke mesin penggerak dan bertugas memberikan daya pada fluida, (2) Turbin, yang bergerak akibat daya yang diberikan oleh fluida melalui momentum sudutnya, (3) reaktor, yang stasioner dan memberikan reaksi momen yang diperlukan dengan mengarahkan fluida dari turbin ke dalam pompa [2]. Masalah penting dalam penerapannya adalah system harus dapat beroperasi pada performance yang optimal. 
Prinsip kerja konverter torsi dimulai dari pompa yang terhubung langsung ke mesin penggerak menerima momen dari mesin penggerak yang memutar pompa menyebabkan fluida bergerak sehingga menghasilkan energi pada fluida. Selanjutnya fluida mengalir dalam konstruksi turbin dan menyalurkan energinya untuk menggerakan turbin [3].

Bentuk geometri penampang aliran mempunyai pengaruh terhadap kinerja setiap mesin fluida yang dirancang dimana untuk kondisi geometri inlet dan outlet yang tetap perubahan penampang daerah impeller mempengaruhi kecepatan aliran di dalamnya [4]. Saat kecepatan turbin semakin meningkat, arah fluida yang meninggalkan turbin cenderung lebih condong dan menyentuh sudu bagian depan reaktor dan menyebabkan reaktor berputar sesuai arah putaran mesin. Pada saat reaktor berputar maka pelipat gandaan momen akan otomatis berhenti. Titik ini selanjutnya disebut titik kopling (clutch point).

Clutch point pada konverter torsi dalam suatu sistem transmisi hidrodinamik merupakan faktor penting dalam pengujian dan operasionalnya karena berhubungan dengan faktor pemanfaatan energi dan nilai ekonomis sistem transmisi tersebut.

Salah satu upaya peningkatan kinerja konverter torsi dilakukan melalui akurasi hasil desain komponen konverter torsi serta penentuan kondisi kerja dalam karakteritik converter, sehingga pemindahan daya dari mesin ke sistem transmisi dapat terjadi pada efisiensi maksimum [2][5][6][7][8].

Terdapat zona-zona dalam kurva karakteristik konverter torsi, yaitu zona sebelum titik kopling, zona dimana momen turbin mendekati momen pompa dan efesiensi mencapai maksimum dan zona selanjutnya. Titik keseimbangan antara momen pompa dan momen turbin disebut titik kopling (clutch point). Pada titik ini reaktor akan akan berputar bersamaan dengan dengan pompa dan turbin sehingga konverter torsi akan berfungsi sebagai kopling hidrodinamik. Titik ini juga merupakan titik kerja optimum dari konverter torsi, $[6,9,10]$. Permasalahan utama dalam desain dan operasi konverter torsi adalah berapa besar pengaruh putaran turbin sehingga tercapai nilai titik kopling (clutch point), Titik ini harus ditentukan melalui analisis pengaruh putaran terhadap parameter energi dimana nilai efesiensi maksimum merupakan titik terbaiknya. Tulisan ini membahas pengaruh rasio putaran (i) terhadap parameter momen dan efisiensi serta menentukan nilai optimum dan clutch point secara teroritis dan experimental. Pada penelitian ini akan dirancang dan diuji karakteristik konverter torsi untuk menentukan clutch point dan parameter-parameter energi dari konverter torsi melalui perhitungan aliran secara teoritis, dan metode kedua adalah memodelkan kondisi experimental dengan terlebih dahulu melakukan desain komponen-komponen utama dengan memperhatikan penampang meridiannya [11]. Kedua hasil ini akan dibandingkan dengan hasil pemodelan yang dilakukan sebelumnya [6].

\section{BAHAN DAN METODE}

\subsection{Komponen-komponen utama konverter torsi.}

Konverter torsi berfungsi memindahkan daya secara halus dengan meredam getaran puntir engine sehingga mesin berputar secara halus dan efisien, [1], meredam fluktuasi momen dari motor penggerak, meredam getaran dan kebisingan pada driveline dan mengatur besar momen secara otomatis sesuai dengan perbedaan kecepatan poros input dan poros output tanpa memerlukan control eksternal. Konverter torsi mentransformasikan momen putar yang diberikan oleh motor penggerak [12].

Komponen utama konverter torsi terdiri atas dua elemen berputar yaitu pompa dan turbin serta reaktor[10]. Pompa terdiri atas sudu-sudu impeller yang berfungsi untuk meningkatkan tekanan fluida dan mengalirkannya langsung ke turbin. Turbin tersusun atas impeller dengan sudu-sudu yang berfungsi untuk menerima energi kinetis dari fluida bertekanan dan dikonversikan menjadi energi mekanik. Reaktor terdiri atas sudu sudu yang berfungsi untuk meningatkan tekanan fluida yang keluar dari turbin dan diarah menuju impeller pompa pada saat putaran turbin rendah. Kopling satu arah (one way clutch) terpasang pada reaktor yang menyebabkan reaktor hanya bisa bergerak searah dengan putaran mesin pada kecepatan turbin tertentu.

Pada putaran turbin tinggi reaktor beralih fungsi menjadi kopling dinamik yang ikut berputar searah putaran turbin dan pompa. Putaran spesifik konverter torsi berada pada kisaran $67-80 \mathrm{rpm}$, sehingga dipilih pompa sentrifugal dan turbin berbentuk turbin francis sebagai komponen utamanya. Konstruksi konverter torsi secara skematis dan konstruksinya digtampilkan pada gambar 2.1. dan 2.2. 

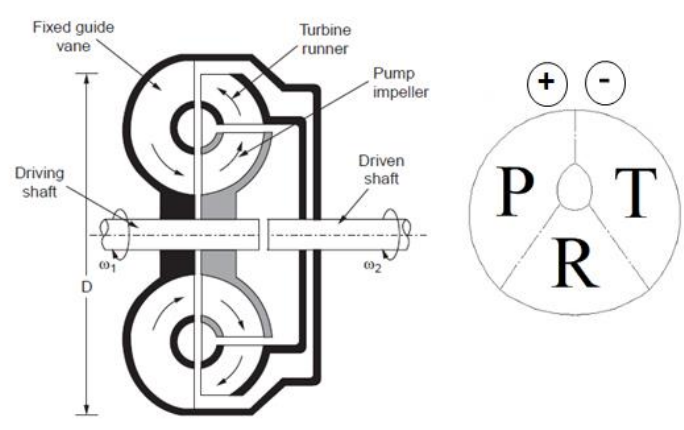

Gambar 2.1 Skema Konverter torsi Sumber : Kothandaraman (2007)

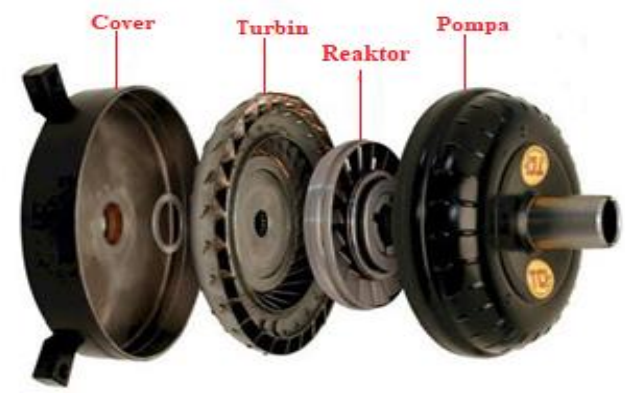

Gambar 2.2 Komponen Konverter torsi Sumber : Slingshot Konverter (2016)

Pompa terhubung ke penggerak utama, turbin terhubung ke poros yang beban dan reaktor yang terpasang diantara turbin dan pompa. Ketiga elemen tersebut tertutup dalam casing yang berisi fluida (oli). Pada konverter torsi, rasio kecepatan berbanding terbalik dengan rasio momen [13]

\subsection{Desain Geometri komoponen-komponen utama}

Desain geometri komonen-komponen utama konverter torsi dilakukan dengan mendapatkan data awal parameter energi dan diameter konverter torsi.

Bentuk dan ukuran impeller stiap komponen konverter torsi ditentukan oleh kecepatan spesifik. Kecepatan spesifik dapat didefinisikan seperti persamaan berikut :

$$
n_{s}=n \frac{Q^{1 / 2}}{H^{3 / 4}}
$$

Dimana : $\mathrm{n}_{\mathrm{S}}=$ Putaran spesifik, $\mathrm{Q}=$ debit aliran $(\mathrm{m} / \mathrm{s}), \mathrm{H}=$ Head pompa $(\mathrm{m}), \mathrm{n}=$ Putaran pompa (rpm). Ukuran-ukuran utama yang telah diketahui dari objek penelitian yang telah ada ditampilkan pada tabel 2.1.

Tabel 2.1. Parameter utama pompa dan turbin

\begin{tabular}{llr}
\hline No & \multicolumn{1}{c}{ Parameter } & Nilai \\
\hline 1. & Debit $[\mathrm{Q}]$ & $0,143 \mathrm{~m}^{3} / \mathrm{s}$ \\
2. & Putaran pompa [n $\left.\mathrm{n}_{\mathrm{p}}\right]$ & $2.800 \mathrm{rpm}$ \\
3. & Diameter pompa = turbin & $260 \mathrm{~mm}$ \\
\hline
\end{tabular}

Selanjutnya penentuan seluruh parameter dan ukuran geometri didasarkan pada perhitungan energi spesifik berdasarkan penyelesaian persamaan Bernoulli untuk dua titik pada garis alir pada inlet dan outlet impeller yang dinyatakan sebagai berikut [11] :

$$
\frac{g H_{T}}{\omega}=\left(r V_{u}\right)_{1}-\left(r V_{u}\right)_{2}
$$

\subsection{Perhitungan parameter-parameter energi.}

Secara teoritis fluida yang mengalir melewati impeller konverter torsi yaitu turbin dan pompa dapat dihitung berdasarkan persamaan 2 dan 2 [11, 12].

dan

$$
M_{p}=\rho Q\left(C_{u 2 p} r_{2 p}-C_{u 2 s} r_{2 s}\right)
$$

$$
-M_{t}=\rho Q\left(C_{u 2 t} r_{2 t}-C_{u 2 p} r_{2 p}\right)
$$

Dimana $M_{P}=$ Momen pada impeller pompa, $M_{T}$ $=$ Momen pada impeller turbin, $C_{u 2 p}=$ kecepatan tangensial pada sisi keluar impeller pompa $(\mathrm{m} / \mathrm{s})$, $C_{u 2 t}=$ kecepatan tangensial pada sisi keluar impeller turbin $(\mathrm{m} / \mathrm{s}), C_{u 2 s}=$ kecepatan tangensial pada sisi keluar impeller reaktor $(\mathrm{m} / \mathrm{s}), \omega_{t}=$ kecepatan sudut turbin $(\mathrm{rad} / \mathrm{s}), r_{2 p}=$ radius sisi keluar pompa $(\mathrm{m}), \mathrm{r}_{2 \mathrm{t}}=$ radius sisi keluar turbin $(\mathrm{m})$, $r_{2 s}=$ radius sisi keluar reaktor $(\mathrm{m}), \rho=$ Masa jenis fluida $\left(\mathrm{kg} / \mathrm{m}^{3}\right)$, dan $Q=$ debit aliran fluida $\left(\mathrm{m}^{3} / \mathrm{s}\right)$

Efisiensi konverter torsi merupakan hubungan antara putaran turbin $\left(N_{T}\right)$ dan momen turbin $\left(M_{T}\right)$ dengan putaran pompa $\left(N_{P}\right)$ dan momen pompa $\left(M_{P}\right)$ dengan diberikan oleh persamaan 4 [2].

$$
\eta=\frac{N_{T} \times M_{T}}{N_{p} \times M_{p}}=i \times \frac{M_{T}}{M_{p}}
$$

Pada kondisi kopling hidrodinamik reaktor yang semula diam ikut berputar bersama pompa dan turbin. Titik kopling dicapai ketika besar momen pompa dan momen turbin sama.

$$
\left(\frac{M_{T}}{M_{P}} \cong 1\right)
$$

\subsection{Pengaturan Instalasi Penelitian}

Agar perhitungan karakteristik system transmisi dalam penelitian ini terarah, maka prosedur perhitungan dilakukan menurut urutan experimental dengan system yang ditunjukan pada gambar 2.1. 


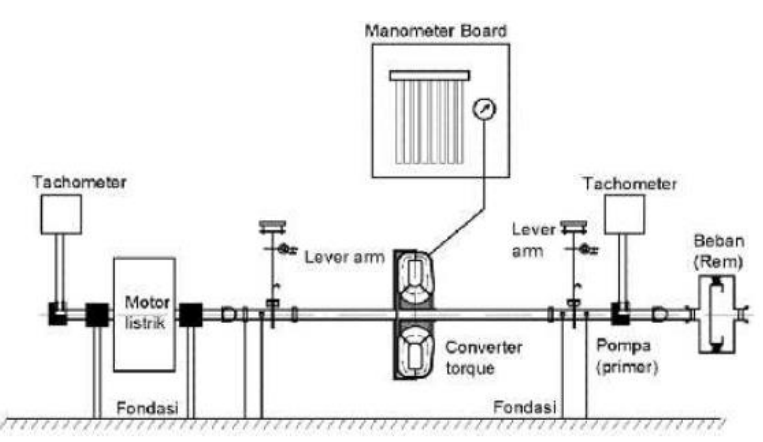

Gambar 2.1 Rangkaian Peralatan Penelitian

Peralatan penelitian dirangkai sesuai dengan gambar 2 yang tersusun atas (1) Motor Penggerak; (2) Kopling; (3) Sensor; (4) Konverter torsi; (5) Beban; (6) Komputer Kontrol; (7) Kartu Siglan Konverter; (8) Stasiun Hidrolik; (9) Kabinet Kontrol.

Prinsip kerja rangkaian penelitian sesuai gambar 2 dimulai dengan motor penggerak melalui kopling meneruskan putaran kepada konverter torsi. motor penggerak terhubung dengan bagian pompa dalam konverter torsi. Pompa kemudian mendorong fluida dalam konverter torsi sehingga menggerakan turbin. Putaran turbin tersebut diteruskan untuk menggerakan beban yang telah dipasang. Fluida di dalam konverter torsi disuplai oleh stasiun hidrolik. Putaran penggerak dan besar beban yang diberikan diatur oleh kabinet kontrol yang terhubung dengan kartu signal dan komputer kontrol. Diantara motor penggerak dan konverter torsi serta konverter torsi dan beban terpasang sensor yang berfungsi untuk mengukur putaran pompa dan turbin, serta mengukur tekanan fluida di dalam konverter torsi. Hasil pengukuran oleh sensor ditransmisikan menuju kartu signal konverter yang terhubung dengan komputer kontrol untuk menampilkan hasil pengukuran.

Rangkaian dan prosedur penelitian diatas kemudian diadaptasi dan disimukasikan.

\subsection{Prosedur Pengujian}

Dalam penelitian ini dilakukan pengukuran jumlah putaran pompa yang terhubung dengan motor penggerak dan putaran turbin yang terhubung langsung dengan beban. Putaran penggerak dibuat konstan sehingga putaran pompa juga konstan. Besar beban divariasikan sehingga putaran turbin juga bervariasi. Besar beban diatur sedemikian hingga diperoleh variasi putaran turbin dengan rasio putaran bervariasi $i=0 \div 1$. Dan karakteristik konvereter torsi digambarkan sebagai berikut :

$$
\left(M_{P}, M_{T}, \eta\right)=\mathrm{f}(i)
$$

Pada kurva ini, ditentukan titik kopling dan semua parameter-parameter opmtimum kinerja konvereter torsi.

\section{HASIL DAN PEMBAHASAN}

\subsection{Ukuran Geometri utama}

Dengan melakukan tahapan desain sebelumnya, maka ukuran gemetri konverter torsi dilakukan dengan pendekatan desain pompa sentrifugal. Hasil desain ukuran geometri objek penelitian ditunjukan pada gambar 2.3.

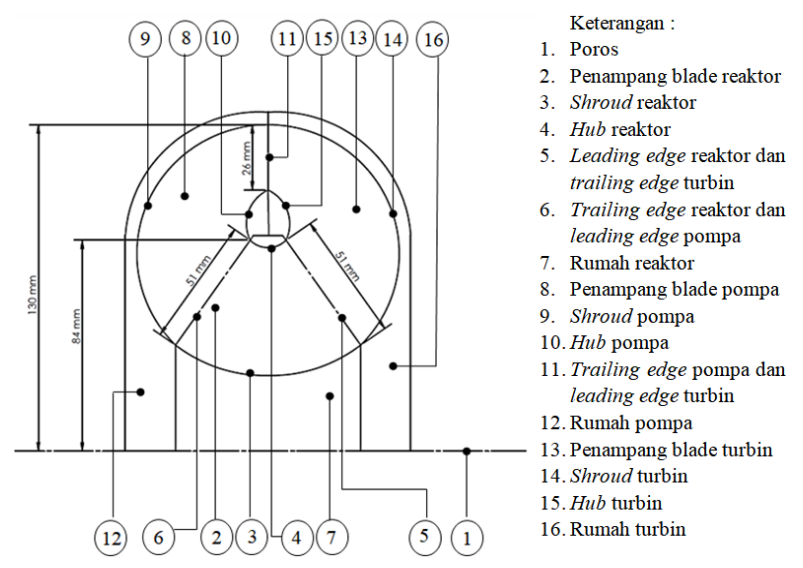

Gambar 4.1 Komponen Penampang Konverter Torsi 2D

Input data konverter torsi yang telah diketahui sebelimnya disajikan dalam tabel 3.1 .

Tabel 3.1. Ukuran geometri dan parameter energi utama

\begin{tabular}{llr}
\hline No & \multicolumn{1}{c}{ Parameter } & \multicolumn{1}{c}{ Nilai } \\
\hline 1. & Debit $[\mathrm{Q}]$ & $0,143 \mathrm{~m}^{3} / \mathrm{s}$ \\
2. & Putaran pompa $\left[\mathrm{n}_{\mathrm{p}}\right]$ & $2.800 \mathrm{rpm}$ \\
3. & Putaran turbin $\left[\mathrm{n}_{\mathrm{p}}\right]$ & $10 \mathrm{rpm}$ \\
4. & Radius outlet pompa $\left[\mathrm{r}_{2 \mathrm{p}}\right]$ & $0,107 \mathrm{~m}$ \\
5. & Radius outlet turbin $\left[\mathrm{r}_{2 \mathrm{t}}\right]$ & $0,051 \mathrm{~m}$ \\
6. & Luas penampang keluar & $0,0175 \mathrm{~m}^{2}$ \\
& pompa[F $\left.\mathrm{F}_{\mathrm{k} 2 \mathrm{p}}\right]$ & \\
7. & Luas penampang reaktor & $0,01911 \mathrm{~m}^{2}$ \\
& {$\left[\mathrm{~F}_{\mathrm{k} 2 \mathrm{~s}}\right]$} & \\
8. & Luas penampang keluar & $0,01911 \mathrm{~m}^{2}$ \\
\hline
\end{tabular}

\subsection{Karakteristik Konverter Torsi}

\subsubsection{Karakteristik teoretis}

Pengaruh perubahan nilai rasio putaran (i) terhadapap momen pompa, momen turbin, dan efisiensi hasil perhitungan teoritis dengan pemodelan aliran satu dimensi ditampilkan pada gambar 5. 


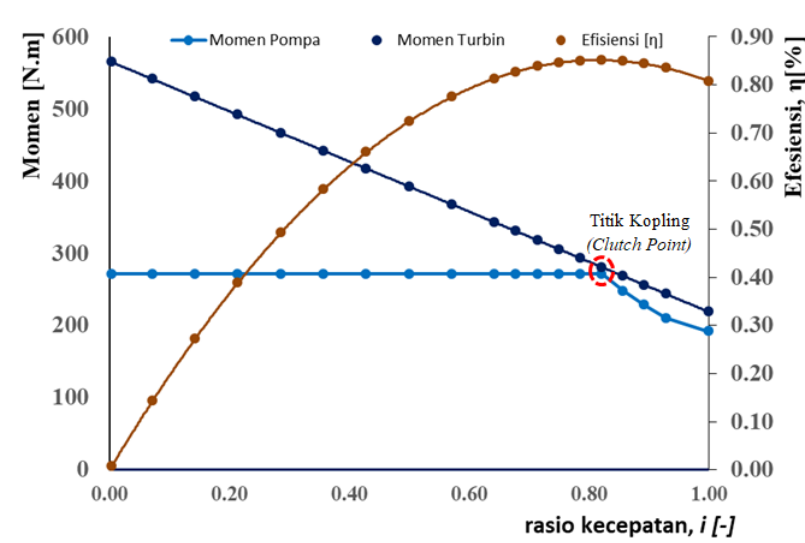

Gambar 5. Kurva karakteristik teoritis

Berdasarkan hasil perhitungan teoritis, pada rasio putaran $i=0,004$ momen yang dihasilkan pompa yaitu sebesar 271,04 N.m. Momen pompa terus konstan seiring dengan peningkatan rasio putaran hingga mencapai rasio putaran $i=0,82$. Melewati rasio putaran $i=0,82$ momen pompa mengalami penurunan proporsional dengan penurunan momen turbin hingga rasio putaran $i=1$ momen yang dihasilkan pompa yaitu sebesar 191,76 N.m. Momen turbin terus mengalami penurunan dengan peningkatan nilai rasio putaran. Pada rasio putaran $i=0,004$ momen pada turbin yaitu sebesar 564,73 N.m. Momen turbin mencapai nilai yang hampir sama dengan momen pompa pada rasio putaran $i=0,82$ dengan nilai momen turbin sebesar 280,82 N.m. melewati rasio putaran $i=$ 0,82 momen turbin juga terus turun seiring dengan momen pompa hingga rasio putaran $i=1$ momen yang dihasilkan turbin yaitu sebesar 218,83 N.m.

Efisiensi secara teoritis pada rasio putaran $i=$ 0.004 mencapai 0,007. Efisiensi terus mengalami peningkatan hingga mencapai nilai maksimum yaitu 0,85 pada rasio putaran $i=0,82$. Ketika rasio putaran $i=0,75-1$ efisiensi mengalami penurunan hingga rasio putaran $i=1$ nilai efisiensi yang dicapi adalah 0,81. Dengan demikian, secara teoritis titk kopling dicapai pada rasio putaran $i=$ 0,82 yang ditunjukan dengan dicapainya efisiensi tertinggi dan nilai momen pompa dan turbin sama.

\subsubsection{Karateristik experimental}

Kurva karakteristik hasil simulasi dengan pemodelan aliran tiga dimensi ditampilkan pada gambar 6.

Pada rasio putaran yang kecil $(i \rightarrow 0)$, momen yang dibutuhkan untuk menggerakan turbin dua kali dari momen yang dihasilakan pompa $\left(\mathrm{M}_{\mathrm{P}}=\right.$ 270,14 N.m dan $\mathrm{M}_{\mathrm{T}}=593,28$ N.m). Selanjutnya momen turbin terus mengalami penurunan seiring dengan penambahan rasio putaran, sedangkan momen pompa cenderung konstan hingga mencapai rasio putaran $i=0,75$ momen pompa mulai mengalami penurunan. Setelah melewati rasio putaran $i=0,75$ momen pompa dan momen turbin menurun hampir bersamaan dengan efesiensi mencapai angka maksimum.

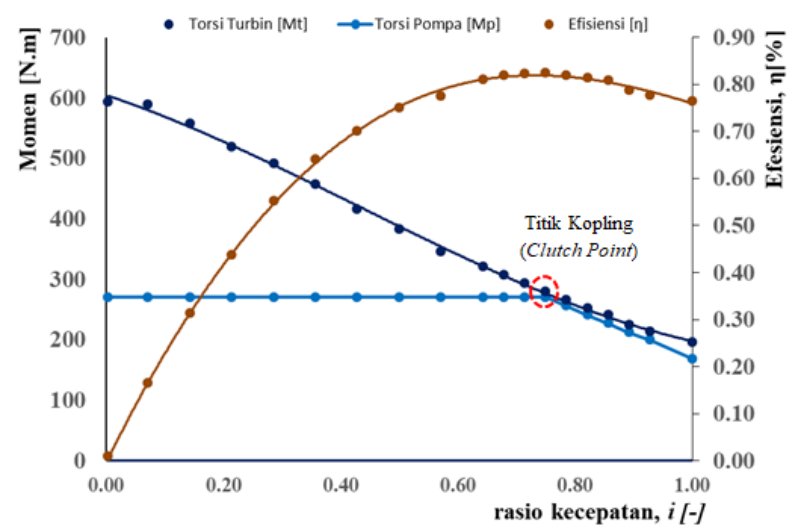

Gambar 6. Kurva karakteristik experimental

\subsection{Penentuan nilai optimum dan zona kerja konverter torsi}

Pada rasio putaran $i=0,75$ besar momen pompa dan momen turbin hampir sama dan efisiensi yang dicapai merupakan efisiensi paling tinggi, sehingga pada pada rasio putaran $i=0,75$ ini dicapai titik kopling (clutch point).

Selanjutnya kondisi kerja konverter torsi dibagi atas tiga zona yang ditampilkan pada gambar 7 , yaitu (1) zona sebelum titik kopling, (2) zona disekitar titik kopling (clutch point), dan (3) zona setelah titik kopling. Zona sebelum titik kopling berkisar antara rasio putaran $i=0,004$ hingga $i=$ 0,71 , pada zona ini reaktor tetap diam sehingga sistem ini bekerja sebagai konverter torsi. Zona disekitar titik kopling (clutch point). berkisar antara rasio putaran $i=0,71$ hingga $i=0,79$. Pada zona disekitar titik kopling (clutch point). dicapai nilai kerja optimum dan reaktor mulai berputar searah dengan putaran pompa dan turbin, serta dicapai keseimbangan antara momen pompa dan momen turbin. Zona setelah titik kopling berkisar antara rasio putaran $i=0,79$ hingga $i=1$, pada zona ini reaktor berputar serahan dengan putaran pompa dan turbin sehingga sistem ini berfungsi sebagai kopling hidrodinamik.

Komparasi perbandingan antara karakteristik konverter torsi hasil perhitungan teoritis aliran satu dimensi dan simulasi aliran tiga dimensi ditampilkan pada gambar 7. Pada perhitungan teoritis aliran satu dimensi titik kopling (clutch point) dicapai pada rasio puataran, $i=0,82$ dan pada simulasi aliran tiga dimensi kopling (clutch 
point) dicapai pada rasio puataran, $i=0,75$. Selisih rasio putaran $(\Delta i)$ pada titik kopling (clutch point) antara dua model ini yang ditunjukan pada zona berwarna pada gambar 4.31 yaitu sebesar 0,07 .

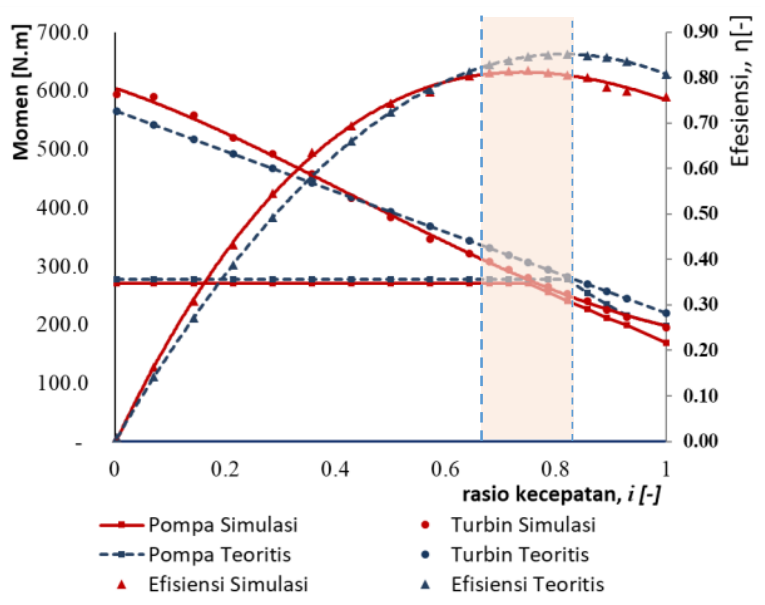

Gambar 7. Komparasi simulasi dan teoritis

Pada start awal $(i \rightarrow 0)$ nilai momen hasil perhitungan teoritis aliran satu dimensi lebih tinggi dibandingkan nilai momen hasil simulasi aliran tiga dimensi. Momen pompa pada kedua model ini sama sama konstan hingga mencapai titik kopling (clutch point) masing masing. Pada titik kopling (clutch point) momen hasil perhitungan teoritis aliran satu dimensi tetap lebih tinggi dibandingkan nilai momen hasil simulasi aliran tiga dimensi dengan selisih momen pompa $\left(\Delta \mathrm{M}_{\mathrm{P}}\right)$ sebesar 0,9 N.m. Pada rasio putaran, $i=0$ nilai momen hasil perhitungan teoritis aliran satu dimensi tetap lebih tinggi dibandingkan nilai momen hasil simulasi aliran tiga dimensi.

Nilai momen hasil perhitungan teoritis aliran satu dimensi pada start awal $(i \rightarrow 0)$, lebih rendah dibandingkan nilai momen hasil simulasi aliran tiga dimensi. Pada rasio putaran $i=0,43$ nilai momen hasil simulasi aliran tiga dimensi menurun dibawah momen hasil perhitungan teoritis aliran satu dimensi. Pada titik kopling (clutch point) selisih momen turbin $\left(\Delta \mathrm{M}_{\mathrm{T}}\right)$ antara kedua model ini yaitu sebesar 0,73 N.m. Pada rasio putaran, $i=0$ nilai momen hasil perhitungan teoritis aliran satu dimensi lebih tinggi dibandingkan nilai momen hasil simulasi aliran tiga dimensi.

Pada start awal $(i \rightarrow 0)$ nilai efisiensi hasil perhitungan teoritis aliran satu dimensi lebih rendah dibandingkan nilai momen hasil simulasi aliran tiga dimensi Pada rasio putaran $i=0,43$ nilai efisiensi hasil simulasi aliran tiga dimensi menurun dibawah momen hasil perhitungan teoritis aliran satu dimensi. Pada titik kopling (clutch point) selisih antara efisiensi $(\Delta \eta)$ pada kedua model ini yaitu sebesar 0,073. Pada rasio putaran, $i=0$ efisiensi perhitungan teoritis aliran satu dimensi lebih tinggi dibandingkan nilai momen hasil simulasi aliran tiga dimensi.

\section{KESIMPULAN}

Berdasarkan hasil perhitungan dan pembahasan, maka dapat disimpulkan bahwa semakin tinggi nilai rasio putaran, nilai momen turbin berkurang sampai mendekati nilai momen pompa pada rasio putaran $i=0,82$ dalam perhitungan teoritis dan $\mathrm{I}=0,75$ pada hasil simulasi 3D. Pada nilai rasio putaran ini diperoleh titik kopling dengan kinerja optimum pada efisiensi maksimum $\eta_{\max }=0,85$ untuk teoritis dan $\eta_{\max }=0,82$ untuk hasil simulasi 3D. Berdasarkan perolehan nilai titik kopling maka diperoleh tiga zona operasi pada kurva karakteristik yaitu kerja konverter, momen turbin tinggi, tetapi efesiensi rendah pada zona $0,004 \leq i \leq 0,71$, kerja optimum pada zona $0,71 \leq i \leq 0,82$, nilai momen turbin $\approx$ nilai momen pompa dan efisiensi mencapai maksimum, dan kerja kopling kecepatan tinggi pada zona $0,82 \leq i \leq 1$, momen turbin dan pompa turun bersamaan, kecepatan tinggi dan efesien. Seilisih nilai optimal hasil perhitungan teoritis dan experimen sebasar $\Delta \eta_{\max }=0,026$ lebih kecil dari perhitungan teoretis.

\section{DAFTAR PUSTAKA}

[1] Kim, B. S., S. B. Ha, W. S. Lim And S. W. Cha (2008) Performance Estimation Model Of A Torque Converter. Part I: Correlation Between The Internal Flow Field And Energy Loss Coefficient. International Journal of Automotive Technology, Vol. 9, No. 2, pp.141-148.

[2] Liu, Cheng, Wei Wei, Qingdong Yan, Brian K. Weaver (2017). Torque Converter Capacity Improvement Through Cavitation Control by Design. Journal of Fluids Engineering Copyright VC 2017 by ASME APRIL 2017, Vol. 139 / 041103-1.

[3] Joydeep, M.BanerjeeJohn J.McPhee. (2012). Graphtheoretic Modeling and Dynamic Simulation of an Automotive Torque Converter, IFAC Proceedings Volumes, Volume 45, Issue 2, Pages 1219-1224.

[4] Rumaherang, W. M. (2020). Pengaruh Rasio Diamater terhadap Parameter-Parameter Energi Turbin Arus Laut Horisontal, Dinamika Teknik Mesin 10(1) (2020) 1-9.

[5] Schweitzer, J and Jeya Gandham (2003). Computational Fluid Dynamics in Torque Converters: Validation and Application. Taylor \& Francis Inc. International Journal of Rotating Machinery, 9: 411-418, 2003. 
[6] Kano, Shinya. Yuji Terasaka. Kouzou Yano. (2004). Prediction of Torque Converter Characteristics by Fluid Flow Simulation. Komatsu Technial Report 2004 VOL. 50 NO.154.

[7] Liu, Chunbao, Changsuo Liu, dan Wenxing Ma (2015). Mathematical Model for Elliptic Torus of Automotive Torque Converter and Fundamental Analysis of Its Effect on Performance. Hindawi Publishing Corporation Mathematical Problems in Engineering Volume 2015.

[8] Brun, Klaus (2015). Hydrodynamic Torque Converters For Oil \& Gas Compression And Pumping Applications: Basic Principles, Performance Characteristics And Applications. Copyright $\subseteq 2015$ by Turbomachinery Laboratory Texas A\&M Engineering Experiment Station.

[9] Tsutsumi, Keisuke, Satoshi Watanabe, Shin-ichi Tsuda, and Takeshi Yamaguch. (2016). Cavitation Simulation of Automotive Torque Converter Using a Homogeneous Cavitation Model. International Symposium on Transport Phenomena and Dynamics of Rotating Machinery.

[10] Rumaherang, W. M. (2019). Evaluasi Karakteristik Energy Torque Converter Berdasarkan Pengaruh Rasio Putaran Terhadap Koefesien Torsi Dan Efesiensi (2019). ISSN: 2620-3995. Prosiding ALE ke-2, Fakultas Teknik Universitas Pattimura Ambon. 2019.

[11] Rumaherang W.M., Ufie R., Latuny J., 2018, Optimization of output parameters of the horizontal tidal turbine by modifying its meridional section, Proceedings of the 2nd Borneo International Conference on Applied Mathematics and Engineering, 2, 16-22.

[12] Artemyeva T.V., T.M, Lisenko, S.P. Stesinn (2007). Gidraulika, Gidromashini I Gidropheumoghivod, Izkadatelskiy Tsentre (Akademiya). Moskva.

[13] Kothandaraman, C. P. and Rudramoorthy R. (2007). Fluid Mechanics and Machinery Second Edition. New Age International (P) Ltd., Publishers. New Delhi. 